\title{
Inferior Pedicle Autoaugmentation Mastopexy After Breast Implant Removal
}

\author{
Johannes Franz Hönig • Hans Peter Frey • \\ Frank Michael Hasse $\cdot$ Jens Hasselberg
}

Received: 20 May 2008/Accepted: 26 May 2009/Published online: 21 February 2010

(C) The Author(s) 2010. This article is published with open access at Springerlink.com

\begin{abstract}
Background A new method of autoaugmentation mammaplasty is presented to correct ptosis and to increase the projection and volume of the breast in patients who would like a reposition augmentation mammaplasty after breast implant removal but do not want a new implant.

Methods Between 1999 and 2007, a total of 27 patients (age $=54 \pm 7.3$ years) underwent mammaplasty using an inferior-based flap of deepithelialized subcutaneous and breast tissue modularized to its pedicle which was inserted beneath a superior pedicle used for correction of ptosis and to increase the projection and apparent volume of the breast.

Results The results confirmed that autoaugmentation mammaplasty of the breast following removal of the implant yields longstanding results. It corrects ptosis and increases the projection and apparent volume of the breast when mastopexy is planned without use of a new implant. Twelve months after surgery the degree of descent of the inframammary fold generally parallels that of the nipple. The mean level of the inframammary fold was below the mean level of the nipple. Postoperatively, the optimum distance had been largely achieved.
\end{abstract}

J. F. Hönig · F. M. Hasse · J. Hasselberg

Paracelsus Clinic Hannover, Hannover, Germany

J. F. Hönig ( $ه)$

Department of Plastic Surgery, University Hospital and Medical

School of Goettingen, Robert-Koch-Street 40, 37075 Goettingen,

Germany

e-mail: info@professor-hoenig.de

H. P. Frey

Clinic im Loewen-Center Luzern, Luzern, Switzerland
Conclusion The advantages of the technique presented here are that it minimizes the skin scar in cases using vertical mammaplasty techniques and optimizes the breast shape after breast implant removal in patients who do not want a new implant.

Keywords Capsular contracture - Breast implant . Autoaugmentation mammaplasty $\cdot$ Mastopexy

In patients who would like a reposition augmentation mammaplasty after breast implant removal but reject the use of a new implant after implant removal because of capsular contracture, autoaugmentation mammaplasty using a deepithelialized inferior-based flap of subcutaneous and breast tissue is an option. It corrects ptosis and increases the projection and apparent volume of the breast when mastopexy is planned without implantation of a new breast implant.

In this article a method and follow-up of autoaugmentation mammaplasty is evaluated using a deepithelialized inferior-based flap of subcutaneous and breast tissue modularized to its pedicle which is inserted beneath a superior pedicle used to correct of ptosis and increase volume of the breast after implant removal. This procedure is suitable for patients who would like a reposition augmentation mammaplasty but do not want a new breast implant after implant removal for capsular contracture.

\section{Patients and Method}

Between 1999 and 2007, a total of 27 patients (age $54 \pm 7.3$ years) underwent an uplift only following breast implant removal with augmentation mammaplasty. Among 
them were 11 smokers. Subglandular implants were noted in 19 of the 27 patients. All patients underwent a thorough, individualized, preoperative evaluation to establish a correct diagnosis, to evaluate asymmetries and implant configuration by MRI, to exclude implant ruptures and malignancies, to estimate the degree of tissue repositioning, and to decide on the level of the new nipple position.

In all patients, the distances between the nipple and the sternal notch $(\mathrm{N}-\mathrm{SN})$, between the nipple and the inframammary fold (N-IMF), and the intermammary distance (IMD) were measured preoperatively at 6 and 12 months (Table 1). The surgical outcome was evaluated according to the analysis obtained before and after surgery and reviewed (Fig. 1). In addition, an independent evaluation of the results at 1 year after the operation on a four-point scale (excellent to poor) was performed. After clinical examination, photographs were taken 6 and 12 months after surgery and reviewed by two residents. The judges reviewed the images independently and recorded the measurements. The results were semiquantitated and a mean score was calculated.

\section{Surgical Techniques}

These procedures have been performed routinely under general anesthesia, with local anesthesia infiltration for homeostasis. Infiltration of the area was performed with a vasoconstricting solution consisting of a dilution of $1 \mathrm{ml}$ of epinephrine in $1000 \mathrm{ml}$ of normal saline. Markings were performed preoperatively with the patient in a standing position [1] (Figs. 2, 3). Once the decision had been made to proceed with mastopexy following explantation of the breast implant without reimplantation, the correct new nipple position was determined. Establishment of the new nipple position was the most important step. After a previous breast augmentation, the nipple may be too high, too low, or just right. Therefore, precisely establishing the new nipple position before explantation was tricky due to the anticipated decrease in breast volume. The nipple position was estimated by measuring the proposed new nipple

Table 1 Pre- and postoperative evaluation of the NAC position $(N=17)$

\begin{tabular}{lccr}
\hline Distance & Preoperative & $\begin{array}{l}\text { 6 Months } \\
\text { postoperative }\end{array}$ & $\begin{array}{l}\text { 12 Months } \\
\text { postoperative }\end{array}$ \\
\hline N-SN & $25.2 \pm 0.9 \mathrm{~cm}$ & $20.2 \pm 0.7 \mathrm{~cm}$ & $21.3 \pm 0.6 \mathrm{~cm}$ \\
N-IMF & $9.3 \pm 0.8 \mathrm{~cm}$ & $7.1 \pm 0.7 \mathrm{~cm}$ & $7.3 \pm 0.3 \mathrm{~cm}$ \\
IMD & $18.4 \pm 1.1 \mathrm{~cm}$ & $18.0 \pm 0.9 \mathrm{~cm}$ & $18.2 \pm 0.7 \mathrm{~cm}$ \\
\hline
\end{tabular}

$N$-SN distance between the nipple and the sternal notch, $N$-IMF distance between the nipple and the inframammary fold, IMD intermammary distance

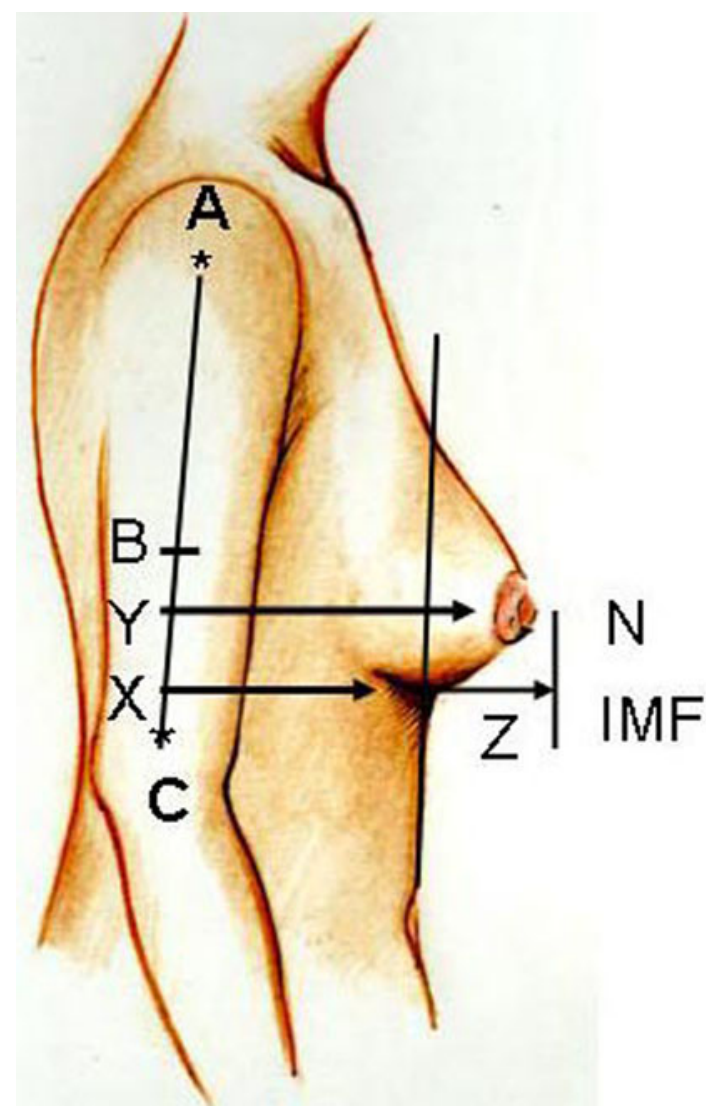

Fig. 1 Schematic drawing of pre- and postoperative evaluations of the nipple and inframammary fold (IMF) position. Level of nipple (N) and level of the inframammary fold (IMF) to $\mathrm{Y}$ measured in the lateral view in a series of autoaugmentation mammaplasties before and after surgery. $\mathrm{Y}$ is the midpoint (B) between the tip of the acromion and the lateral epicondyle minus $1 \mathrm{~cm}$. $\mathrm{X}$ is the level of IMF measured to $\mathrm{Y}$

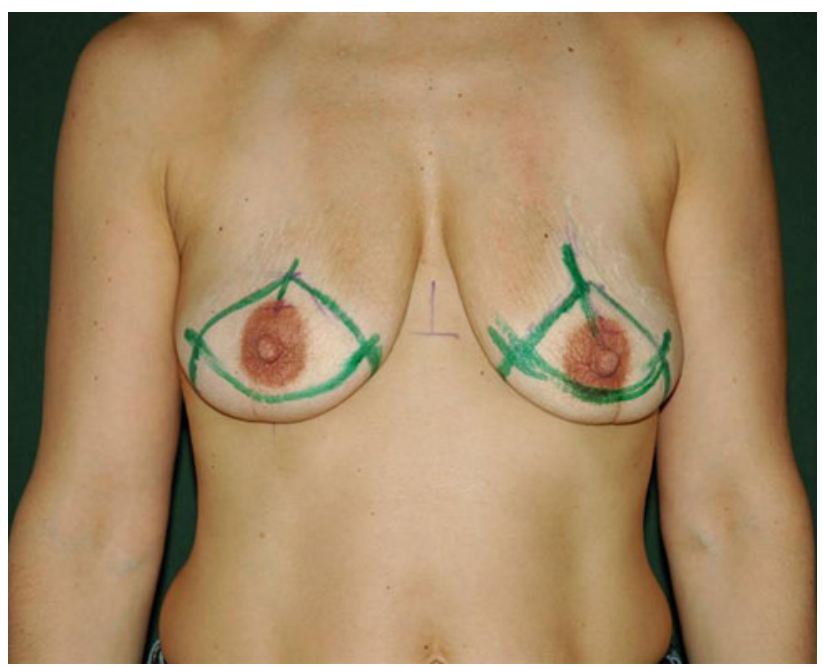

Fig. 2 Preoperative markings of a patient undergoing autoaugmentation mammaplasty 


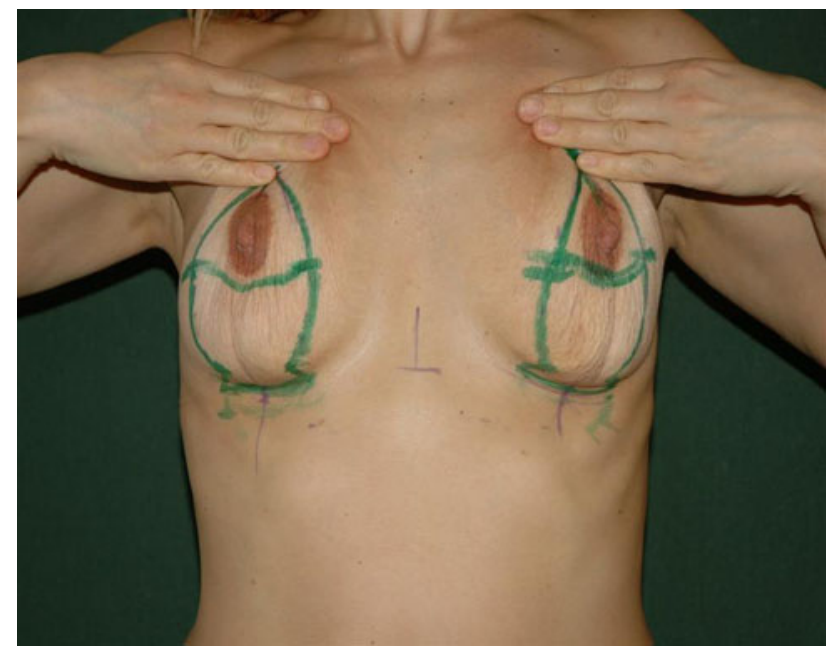

Fig. 3 Preoperative markings of a patient undergoing autoaugmentation mammaplasty using a deepithelialized inferior-based flap of subcutaneous and breast tissue modulized to its pedicle which is inserted beneath a superior pedicle used for correction of ptosis and to increase the projection and apparent volume of the breast after implant removal

position from the fixed point of the suprasternal notch (SSN). The final nipple position was established after explantation and reconfiguration of the breast tissue with the patient sitting up at $90^{\circ}$ on the operating table.

The breast tissue was reconfigured to produce the best possible shape by narrowing the base dimension and position of the breast. This usually entails central transposition of tissue. This was achieved using a superior pedicle mastopexy technique with a deepithelialized inferior-based flap of subcutaneous and breast tissue as a foundation on top of which the superior nipple-areola (NAC) complex was seated (Figs. 4, 5, 6, 7, 8, 9).

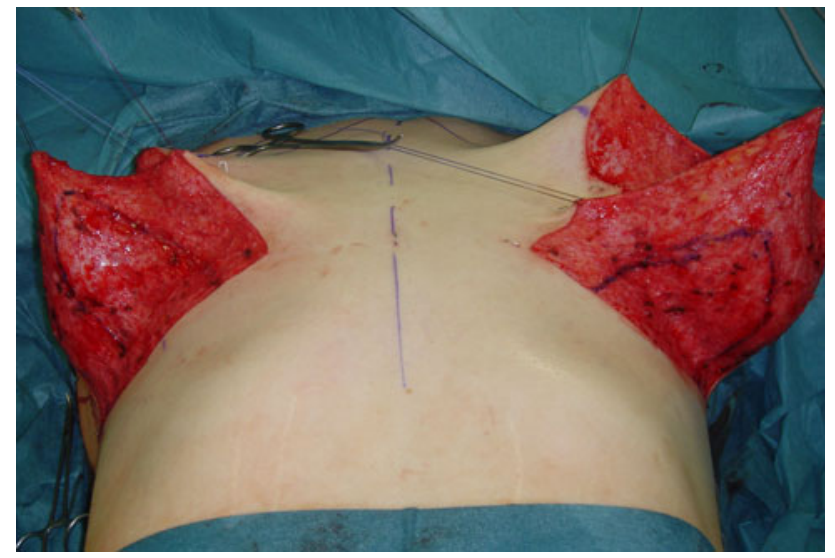

Fig. 4 Intraoperative view of a patient undergoing autoaugmentation mammaplasty with a superior pedicle mastopexy technique using a deepithelialized inferior-based flap of subcutaneous and breast tissue as a foundation on top of which the superior nipple-areola (NAC) complex was seated. The inferior pedicle was drawn $7-8 \mathrm{~cm}$ wide and $2-4 \mathrm{~cm}$ long below the NAC and not less than $2 \mathrm{~cm}$ thick

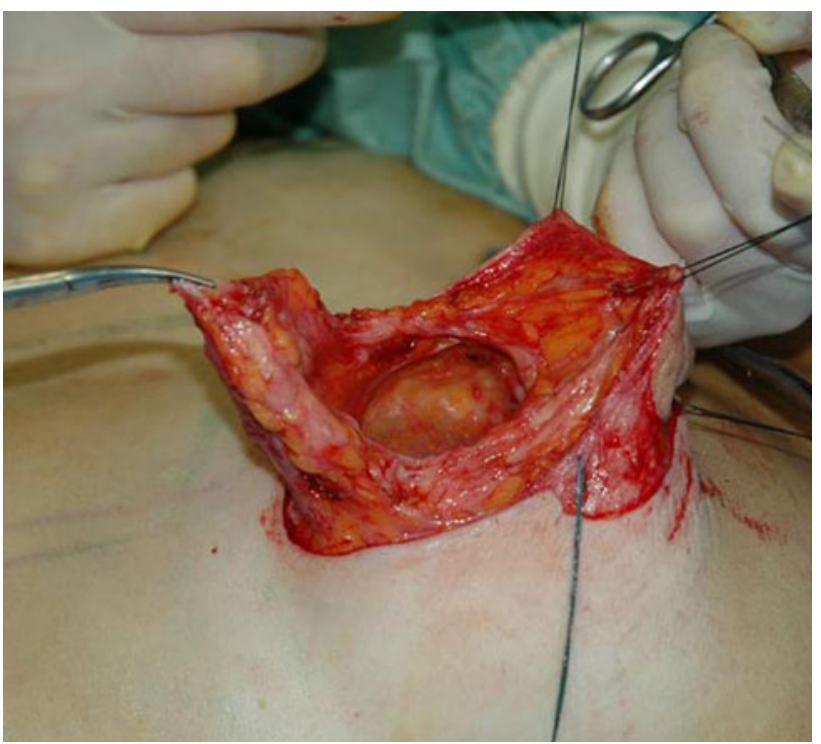

Fig. 5 Intraoperative view of a patient undergoing autoaugmentation mammaplasty with a superior pedicle mastopexy technique using a deepithelialized inferior-based flap; note removal of the encapsulated implant

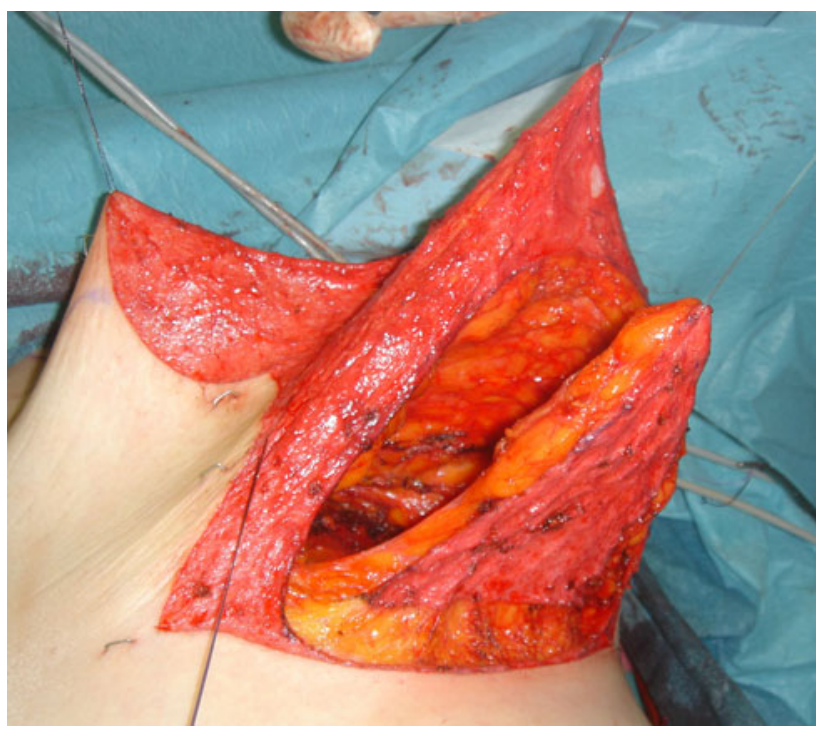

Fig. 6 Intraoperative view of a patient undergoing autoaugmentation mammaplasty: oblique view of the deepithelialized inferior-based flap. Note the thickness of the flap

The inferior pedicle was drawn $5-6 \mathrm{~cm}$ wide, $2-4 \mathrm{~cm}$ long below the NAC, and not less than $2 \mathrm{~cm}$ thick (Figs. 4, 5,6). After deepithelialization of the periareolar and the pedicle area, the marked flap was incised. After removing the encapsulated implant without achieving a complete capsulectomy and undermining the parenchyma toward the upper pole, the inferior deepithelialized pedicle was raised and the subcutaneous tissue as well as the breast parenchyma of the central lower breast was folded up underneath 

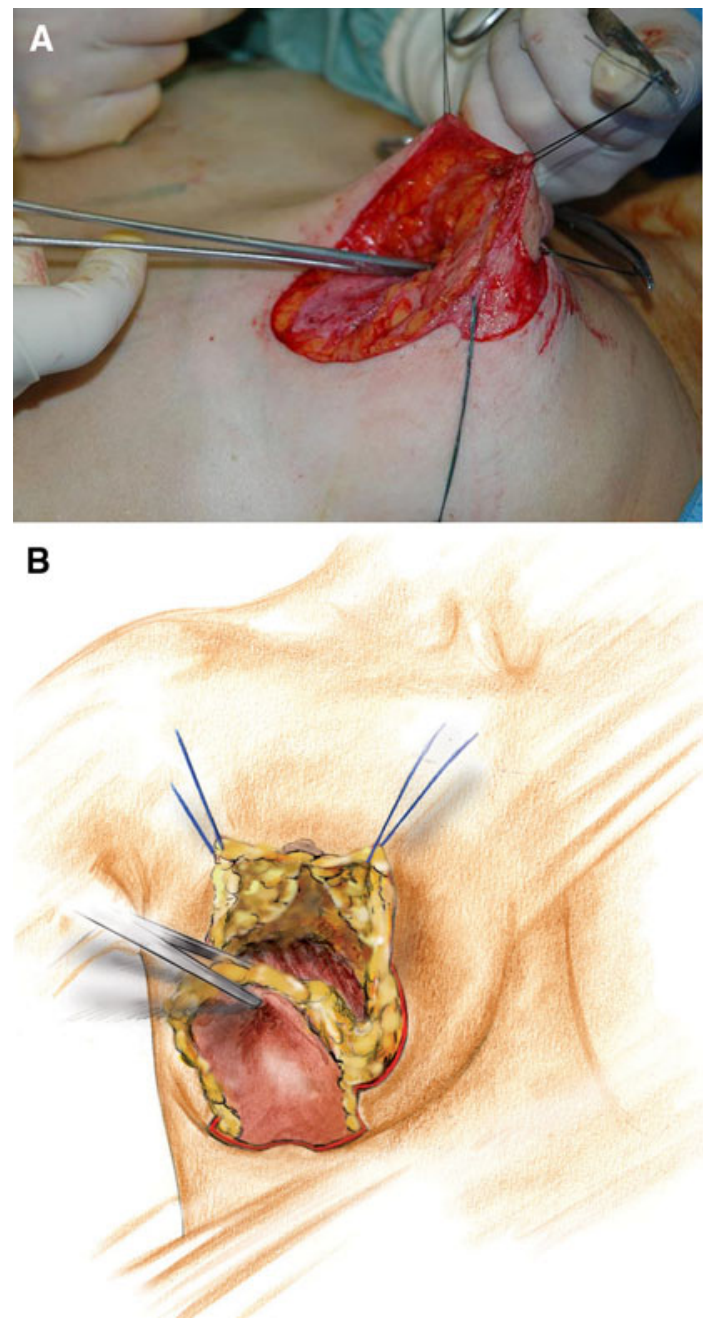

Fig. 7 a Intraoperative view of a patient undergoing autoaugmentation mammaplasty; lateral view of the deepithelialized inferior-based flap; after removing the encapsulated implant, leaving the capsule attached to the thoractic wall, and after underming the parenchyma toward the upper pole, the inferior deepithelialized pedicle was raised and the subcutaneous tissue as well as the breast parenchyma of the central lower breast were folded up underneath the nipple and areola to maximize upper breast volume. b Schematic drawing of autoaugmentation mammaplasty. The pedicle is folded up underneath the nipple and fixed to the capsular tissue on the thoractic wall respectively pectoralis major fascia without any restriction behind the NAC

the nipple and areola to maximize upper-breast volume (Figs. 7, 8). It is critical to optimize upper-pole fullness and projection of the breast using the inferior pedicle. Therefore, it is helpful to incise the deepithelialized dermis at the base of the inferior pedicle, allowing the flap to be mobilized upward (Fig. 6). After flap mobilization, the pedicle, with its inner lined capsular tissue, was fixed to the fibrotic capsule tissue on the chest wall (pectoralis major muscle fascia) without any restriction behind the NAC (Fig. 8). After the flap was tacked to the chest wall with $2 \times 0$ PDS sutures, closure of the medial and lateral pillars over the

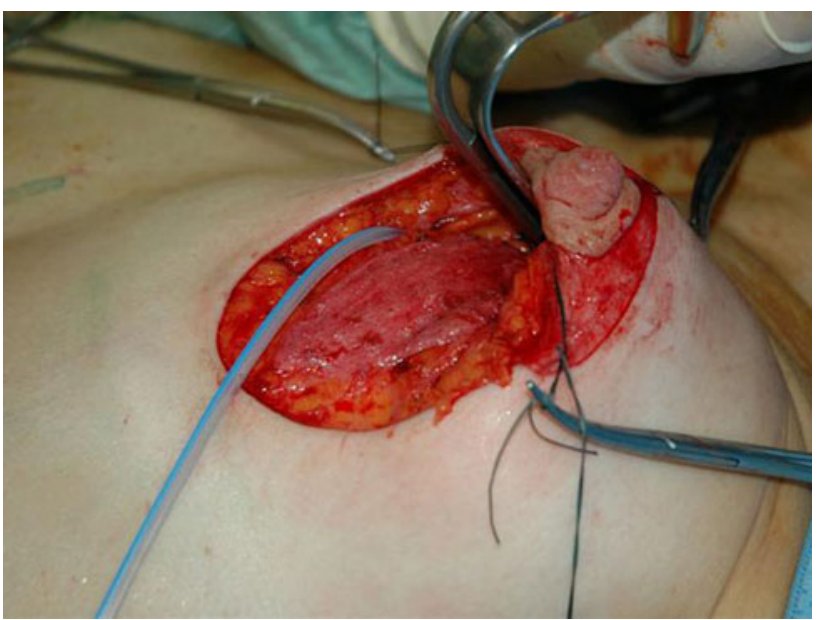

Fig. 8 Intraoperative view of a patient undergoing autoaugmentation mammaplasty. Inferior view of the deepithelialized inferior-based flap which is fixed to the thoractic wall without any restriction behind the NAC

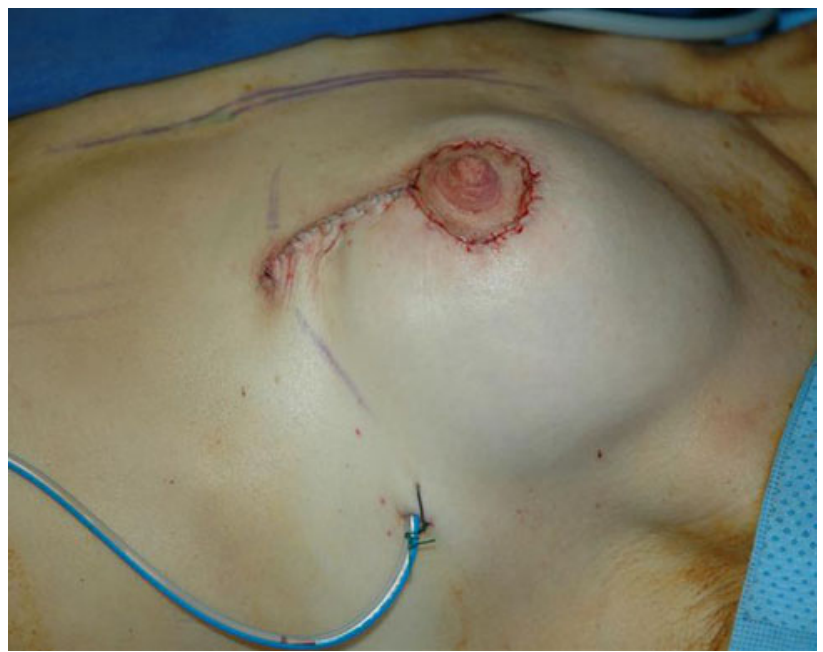

Fig. 9 Intraoperative view of a patient undergoing autoaugmentation mammaplasty using the vertical mastopexy technique

flap optimized upper-pole fullness (Fig. 9). Closure of the periareolar incision was performed by means of a round block technique using a purse string suture as described by Hammond et al. [2].

\section{Results}

The median observation time was $13 \pm 2.1$ months. Immediate healing was achieved without complications, adverse reactions, or side effects. All patients healed uneventfully without any postoperative problems. No swelling or seromatous fluid collection necessitated a second procedure or prolonged drainage. No partial or total necrosis of the nipple and no hypertrophic scarring were 
Table 2 Pre- and postoperative evaluation of the nipple $(\mathrm{N})$ and inframammary fold (IMF) position $(N=27)$

\begin{tabular}{llll}
\hline Distance & Preoperative & $\begin{array}{l}\text { 6 Months } \\
\text { postoperative }\end{array}$ & $\begin{array}{l}\text { 12 Months } \\
\text { postoperative }\end{array}$ \\
\hline $\mathrm{N}$ to $\mathrm{Y}$ & $4.2 \pm 3.2 \mathrm{~cm}$ & $1.3 \pm 2.1 \mathrm{~cm}$ & $1.6 \pm 1.8 \mathrm{~cm}$ \\
$\mathrm{IMF}$ to $\mathrm{Y}$ & $5.8 \pm 2.2 \mathrm{~cm}$ & $4.5 \pm 1.8 \mathrm{~cm}$ & $4.9 \pm 1.7 \mathrm{~cm}$
\end{tabular}

Level of nipple (N) and level of the inframammary fold (IMF) to $\mathrm{Y}$ measured in the lateral view in a series of autoaugmentation mammaplasties before and after surgery. $\mathrm{Y}$ is the midpoint between the tip of the acromion and the lateral epicondyle minus $1 \mathrm{~cm}$

detected. The aesthetic results were considered good to excellent in 23 cases and satisfactory in 4 cases (Fig. 10). The contour results were stable in long-term follow-up evaluation (Figs. 11-13).

After 6 and 12 months postsurgery, the degree of descent of the IMF generally parallels that of the nipple (Table 2). The mean level of the inframammary fold was

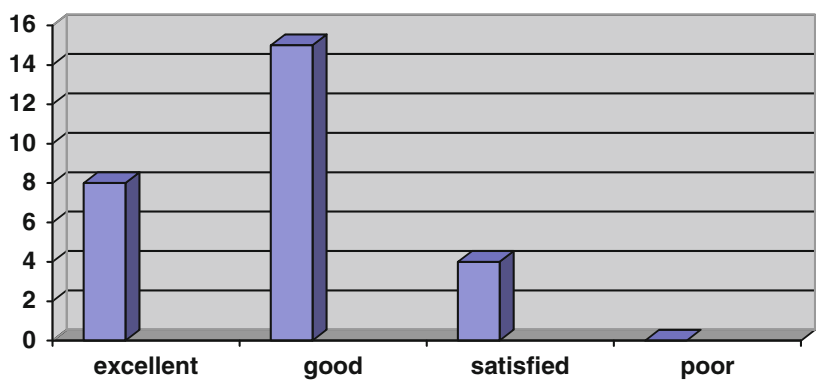

Fig. 10 Independent evaluation of the results at one post surgery $(N=27)$

below the mean level of the nipple. Postoperatively, the optimum distance had been largely achieved. There was a descent of the IMF and of nipple projection as whole-breast ptosis proceeded (Table 3 ). In addition, the pedicle allows elevation of the IMF and reduction of the base.
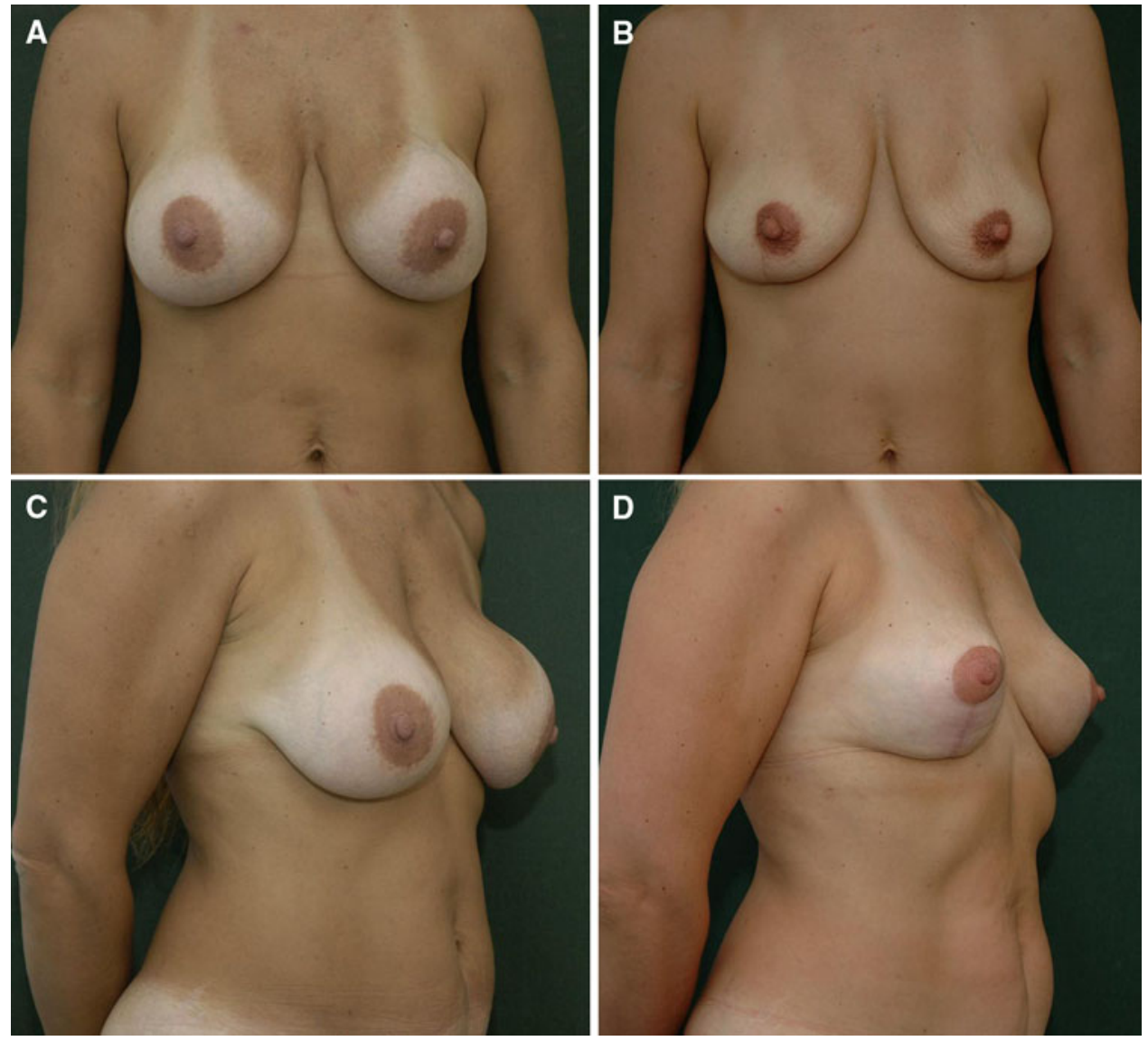

Fig. 11 a Preoperative frontal view of a patient undergoing implant removal in combination with autoaugmentation mammaplasty using an inferior-based deepithelialized flap in combination with a vertical mastopexy technique for breast enhancement. b Postoperative frontal view 12 months after surgery. c Preoperative oblique view. d Postoperative oblique view with good projection of the NAC. Note the position of the NAC which is above the IMF 

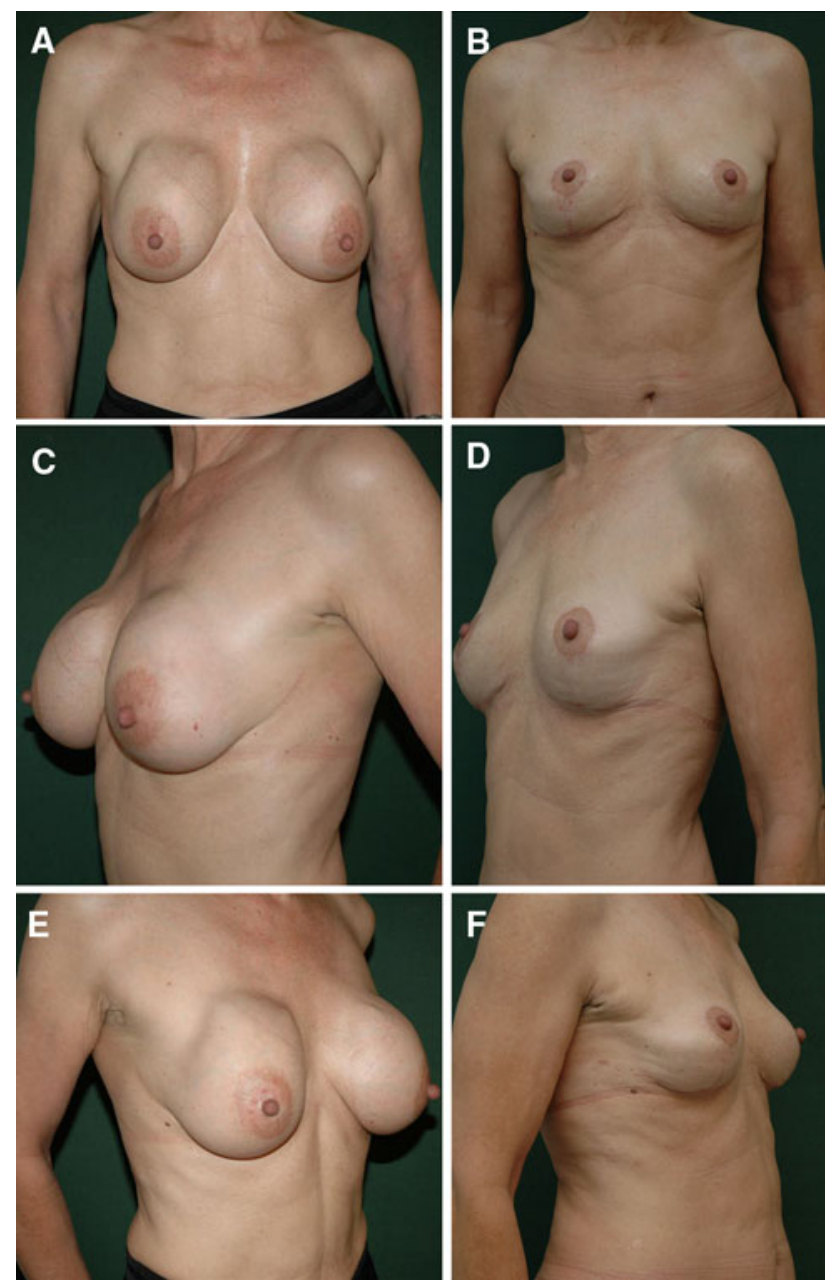

Fig. 12 a Preoperative frontal view of a patient with Baker IV capsular contracture. She rejected use of a new implant and therefore underwent autoaugmentation mammaplasty using an inferior-based deepithelialized flap. b Postoperative frontal view 12 months after surgery. c Preoperative left oblique view. Note the heavy and disfigured breasts. d Postoperative left oblique view after autoaugmentation mammaplasty; the breasts were smaller with upper-pole fullness and projection of the NAC over the IMF. e Preoperative right oblique view. Note the heavy and disfigured breasts. f Postoperative right oblique view after autoaugmentation mammaplasty

\section{Discussion}

The goal of autoaugmentation mammaplasty using an inferior pedicle is to give volume to the breast again after implant removal without reimplantation or in cases of breast reduction. Using an inferior pedicle as first described by Ribeiro [3, 4] in reduction mammaplasty, the volumetric transfer of the back of the central pedicle will augment breast projection, especially after implant removal. With this procedure, breast tissue is taken from the area where there is excess to the area where there is a deficit. Thus, the pedicle works as an auto (natural) breast prosthesis and also provides good vascularization of the lower portion of the breast.

The inferior pedicle not only has the advantage of a conization effect from vertical reduction of the technique described by Lassus [5], Marchac and de Olarte [6], Lejour [7], and later modified by Mottura [7], it also allows shifting of the pedicle tissue under the central parenchyma of the breast behind the NAC to the area that is usually loose and empty [1, 3, 4, 8-13].

From a vascular point of view, the dermoglandular inferior pedicle allows better lateral and medial reshaping than do superior-based flaps $[12,13]$. This is because the inferior-based flap originates from a dermolipoglandular pedicle that is based on the fourth, fifth, and sixth intercostals perforating vessels of the internal mammary vessel. Even the dermis of the flap can be divided, as long as the inferior portion of the transversely oriented septum of the breast is not violated, because the perforators are located along the septum [14].

Despite the fact that the Ribeiro inferior pedicle is a widely used procedure in reduction mammaplasty, it has been criticized as being prone to "bottoming out" [8-10, 14-16]. To obtain a predictable and long-lasting stable breast shape by avoiding bottoming out, fixation and retention of the flap to the chest wall are imperative. Therefore, efforts to prevent bottoming out have involved variations in the suspension of the inferior pedicle $[8,14$ 18]. Daniel [17], de Cerqueira [18], Graf and Biggs [8], Hinderer [19], Caldeira and Lucas [20], Fontana and Muti [21], and Gracia Padron [22] all have described chest wallbased flaps passed through loops of the pectoralis major muscle with good effect. We believe the same effect can be achieved with much less effort in patients with capsular contracture who reject insertion of new implants by suturing the pedicle, with its inner-lined capsular tissue, to the thick fibrotic capsule tissues on the chest wall after implant removal so that the inner surfaces of the capsular tissue are faced and sutured together. Once the "fibrosis" of the sutured capsular tissue is established, the entire pedicle is expected to maintain its position. This avoids the bottoming out because the flap is attached to the solid capsular tissue, and also the weight of the remaining breast is reduced. Thus, this allows elevation of the inframammary fold and reduction of the base, as our results confirmed. By suturing the lateral and medial glandular edges in three layers and the base of the gland over the pedicle, the areola will gain additional projection.

To achieve aesthetically pleasant pole fullness, a long volumetric pedicle is almost always needed in reaugmentation mammaplasty when autoaugmentation mammaplasty is planned without an implant. Therefore, the volume of the inferior pedicle depends on the distance between the areola and the inframammary fold. The 

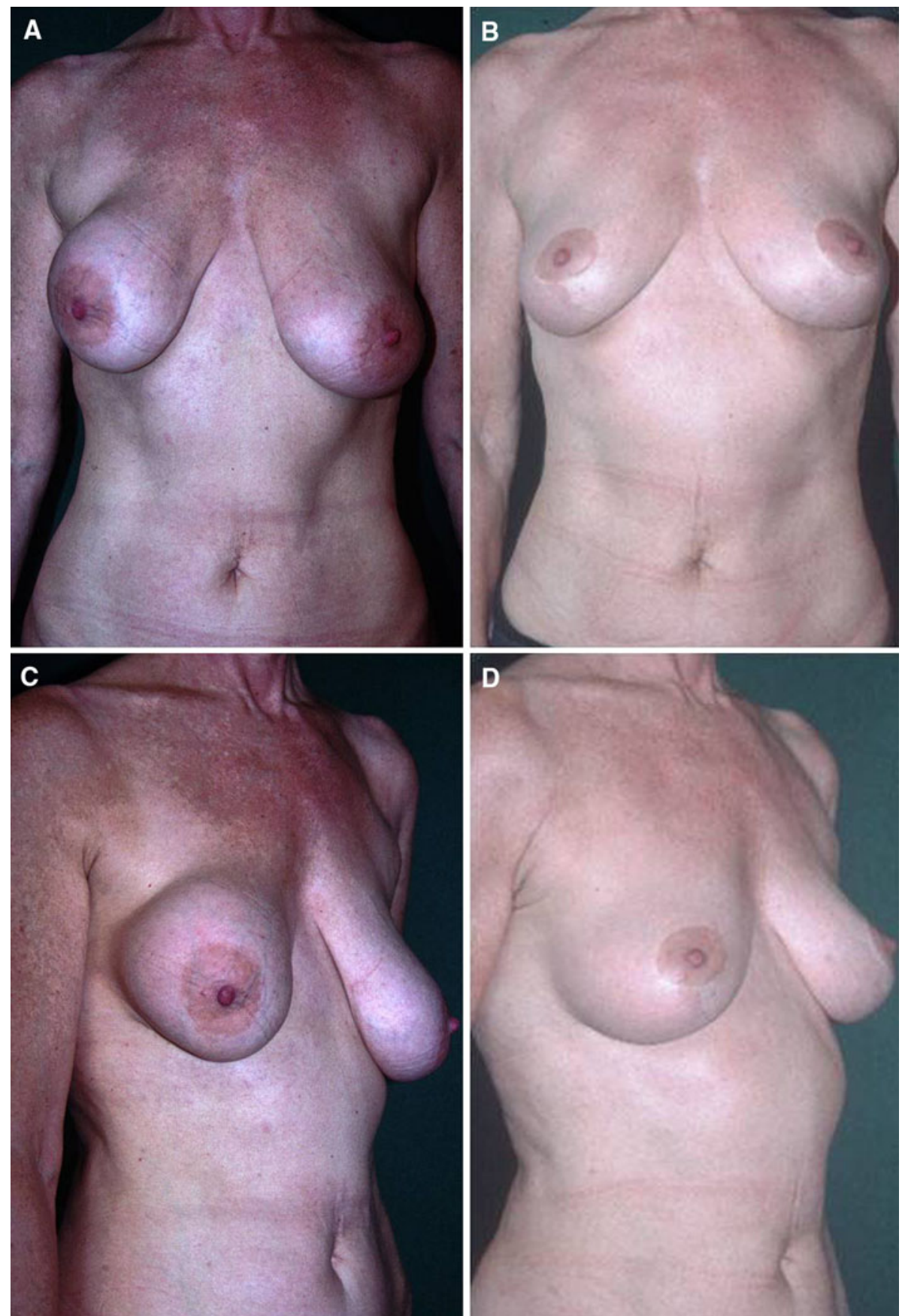

Fig. 13 a Preoperative oblique view of a patient with Baker IV capsular contracture on the right side and Baker III on the left side with severe ptosis on the left. b Postoperative frontal view 12 months after surgery; the implants were removed and reconstruction of the breasts was by autoaugmentation mammaplasty using an inferiorbased deepithelialized flap in combination with a vertical mastopexy

technique with a short horizontal excision line for breast enhancement. c Preoperative oblique view; note the heavy breasts with the encapsulated implant. d Postoperative oblique view after autoaugmentation mammaplasty and implant removal. The breasts were smaller with upper-pole fullness and projection of the NAC over the IMF

Table 3 Pre- and postoperative evaluation of the nipple projection $(N=27)$

\begin{tabular}{llll}
\hline Distance & Preoperative & 6 Months postoperative & 12 Months postoperative \\
\hline Npr to $\mathrm{Ch}=\mathrm{z}$ & $4.6 \pm 1.2 \mathrm{~cm}$ & $5.2 \pm 1.1 \mathrm{~cm}$ & $4.9 \pm 0.6 \mathrm{~cm}$ \\
\hline
\end{tabular}

Projection of nipple (Npr) to a perpendicular line of the chest $(\mathrm{Ch})$ wall in patients standing erect in a series of autoaugmentation mammaplasties before and after surgery. $\mathrm{z}=$ distance from nipple to chest wall 
inferior pedicle's upper limit is $1 \mathrm{~cm}$ below the inferior edge of the areola. The distance between the lateral and medial borders of the breast pillars and the base of the pedicle, which extends to the inframammary crease, defines the size of the flap, which is approximately $6-8 \mathrm{~cm}$ wide and $4 \mathrm{~cm}$ thick.

Compared to a superior pedicle flap or a McKissock [23] flap, which is folded on itself, the inferior pedicle has the disadvantage in that in cases of a short pedicle, it cannot be folded on itself. Therefore, the milk ducts will not recanalize because the deepithelialized dermoglandular surface is in contact with the pectoralis major fascia. Compared to the lateral pedicle with its limited recruitment of tissue which is advocated in some cases in reduction mammaplasty procedures for autoaugmentation [24], the inferior pedicle is designed to give better breast shape with upperpole fullness and more volume, which is imperative in reautoaugmentation after implant removal without using a new implant. Ribeiro's technique, an inferior pedicle flap rotated in the upper pole, provides improvement in upperbreast fullness in autoaugmentation mammaplasty, as our results confirmed.

To stabilize the shape and the size of the areola, which is mandatory, we use a round block suture, as described by Hammond et al. [2]. In combination with this pedicle, this provides a conical shape to the breasts with good projection and gives good long-term results.

We believe that the autoaugmentation mammaplasty procedure is suitable for patients who would like a repositioning or reaugmentation of their breasts with autogeneous tissue, thereby avoiding insertion of a new implant. The technique described here can be used with standard inverted $\mathrm{T}$ incisions, vertical incisions with short incision components, or pure vertical incisions. Depending on the patient's desires and volume of the breast, a bipedicle flap can also be used for reautoaugmentation in certain cases, especially when reaugmentation has been performed through inframammary and periareolar incisions.

\section{Conclusion}

Autoaugmentation of the breast can be achieved following implant removal when mastopexy is planned without insertion of a new implant. This procedure corrects ptosis and increases the projection and apparent volume of the breast. The advantages of the technique are that it both minimizes the skin scar and optimizes the shape following upper-pole fullness and suture fixation of the pillars of the breast parenchyma. In addition, autoaugmentation mammaplasty is a good technique for patients desiring only an uplift following breast implant removal.
Open Access This article is distributed under the terms of the Creative Commons Attribution Noncommercial License which permits any noncommercial use, distribution, and reproduction in any medium, provided the original author(s) and source are credited.

\section{References}

1. Ramirez OM (2008) The owl technique combined with the inferior pedicle in mastopexy. Aesthetic Plast Surg 32:16-17

2. Hammond DC, Khuthaila DK, Kim J (2007) The interlocking Gore-Tex suture for control of areolar diameter and shape. Plast Reconstr Surg 119:804-809

3. Ribeiro L, Accorsi A Jr, Buss A, Marcal-Pessoa M (2002) Creation and evolution of 30 years of the inferior pedicle in reduction mammaplasties. Plast Reconstr Surg 110:960-970

4. Ribeiro L (1975) A new technique for reduction mammaplasty. Plast Reconstr Surg 55:330-334

5. Lassus C (1987) Breast reduction: evolution of a technique-a single vertical scar. Aesthetic Plast Surg 11:107-112

6. Marchac D, de Olarte G (1982) Reduction mammaplasty and correction of ptosis with a short inframammary scar. Plast Reconstr Surg 69:45-55

7. Lejour M (1993) Vertical mammaplasty. Plast Reconstr Surg 92(5):985-986

8. Mottura AA (2003) Circumvertical reduction mastoplasty: new considerations. Aesthetic Plast Surg 27:85-93

9. Graf R, Biggs TM, Steely RL (2000) Breast shape: a technique for better upper pole fullness. Aesthetic Plast Surg 24:348-352

10. Graf R, Biggs TM (2002) In search of better shape in mastopexy and reduction mammoplasty. Plast Reconstr Surg 110:309-317

11. Graf R, Biggs TM (2006) Mastopexy with a pectoralis loop. In: Spear S (ed) Surgery of the breast, 2nd edn. Lippioncott Williams \& Wilkins, Philadelphia, pp 1008-1009

12. Ramirez OM (2002) Reduction mammaplasty with the "owl" incision and no undermining. Plast Reconstr Surg 109:512-522

13. Loustau HD, Mayer HF, Sarrabayrouse M (2008) The owl technique combined with the inferior pedicle in mastopexy. Aesthetic Plast Surg 32:11-15

14. Widgerow $\mathrm{AD}$ (2005) Breast reduction with inferior pedicle fascial suspension. Aesthetic Plast Surg 29:532-537

15. Rohrich RJ, Gosman AA, Brown SA, Reisch J (2006) Mastopexy preferences: a survey of board-certified plastic surgeons. Plast Reconstr Surg 118:1631-1638

16. Pennington DG (2006) Improving the results of inferior pedicle breast reduction using pedicle suspension and plication. Aesthetic Plast Surg 30:390-394

17. Daniel MJ (1994) Mamoplastia com retahlo de musculo peitoral. Arch Catarinense Med 23(Suppl 1):119

18. de Araujo Cerqueira A (1998) Mammoplasty: breast fixation with dermoglandular mono upper pedicle flap under the pectoralis muscle. Aesthetic Plast Surg 22:276-283

19. Hinderer U (1972) Plastia mamaria modelante de dermopexia y retromamaria. Rev Esp Cir Plast 5:521

20. Caldeira AML, Lucas A (1997) Mammaplasty with triple interposition of glandular flaps. Technical note. Ann Chir Plast Esthet 42:238-246

21. Fontana AM, Mutt E (1982) Apprunti sulla mastoplastica riduttiva. Una tecnica mastopessi. Riv Ital Chir Plast 14:139-141

22. Gracia Padron J (1972) Mammareduktionsplastik. Transact III, Tagung der Vereinigung der Deutschen Plastischen Chirurgen, Köln

23. McKissock PK (1972) Reduction mammaplasty with a vertical dermal flap. Plast Reconstr Surg 49:245-252

24. Hall-Findlay EJ (2002) Pedicles in vertical breast reduction and mastopexy. Clin Plast Surg 29:379-391 